\title{
Caracterização química e física de batatas 'Ágata' minimamente processadas, embaladas sob diferentes atmosferas modificadas ativas
}

\author{
Lívia Lacerda Oliveira Pineli(1), Celso Luiz Moretti( ${ }^{(2)}$, Gustavo Costa Almeida(3) ${ }^{(3 n a ~ C e c i ́ l i a ~ A m o r i m ~ O n u k i(4) ~}$ \\ e Aline Brum Gomes Nascimento(4)
}

\begin{abstract}
(1)Universidade de Brasília, Dep. de Nutrição Humana, Campus Universitário da Asa Norte, Caixa Postal 4370, CEP 70910-900 Brasília,DF. E-mail: liviapineli@yahoo.com.br (2)Embrapa Hortaliças, BR-060 Rod. Brasília/Anápolis, Km 09, Caixa Postal 218, CEP $70359-970$ Brasília, DF. E-mail: celso@cnph.embrapa.br (3)Universidade Federal de Lavras, Dep. de Ciência dos Alimentos, Campus Universitário, Caixa Postal 3037 , CEP 37200-000 Lavras MG. E-mail: gcalmeida@ufla.br (4)Faculdades Integradas da Terra de Brasília, Quadra 203, Área Especial Lote 32, CEP 72610-300 Recanto das Emas, DF.E-mail: ana_ceci_lia@yahoo.com.br, abgomes@yahoo.com.br
\end{abstract}

\begin{abstract}
Resumo - O objetivo deste trabalho foi avaliar as alterações químicas e físicas em batatas ‘Ágata’ minimamente processadas, embaladas sob diferentes atmosferas, durante o armazenamento refrigerado. Batatas ‘Ágata’ foram minimamente processadas como minibatatas e embaladas em filmes de náilon multicamadas. Os tratamentos aplicados no momento da embalagem foram o vácuo parcial e as misturas $10 \% \mathrm{CO}_{2}, 2 \% \mathrm{O}_{2}, 88 \% \mathrm{~N}_{2}$ ou $5 \% \mathrm{CO}_{2}$, $5 \% \mathrm{O}_{2}, 90 \% \mathrm{~N}_{2}$. Em seguida, foram armazenadas a $5^{\circ} \mathrm{C}$. A cada três dias, amostras foram avaliadas quanto ao índice de escurecimento, atividade da polifenoloxidase e peroxidase, firmeza, sólidos solúveis totais e acidez titulável. O armazenamento sob vácuo parcial foi o mais eficaz no controle do escurecimento, da minimização da atividade da polifenoloxidase e da peroxidase, prevenindo alterações nos teores de sólidos solúveis totais, redução da firmeza, encharcamento da embalagem e maior acidez titulável. Os demais tratamentos apresentaram rápido desenvolvimento do escurecimento, aumento de firmeza em decorrência de ressecamento dos tubérculos, elevação nos sólidos solúveis totais e menor desenvolvimento da acidez em comparação ao tratamento sob vácuo parcial. A utilização de vácuo parcial foi a mais recomendada para a manutenção da qualidade das minibatatas. Todavia, outros tratamentos que busquem a manutenção da firmeza e frescor, sem o desenvolvimento de offflavors e sem escurecimento, devem ser avaliados.
\end{abstract}

Termos para indexação: processamento mínimo, batata, escurecimento, atmosfera modificada.

\section{Chemical and physical characterization of fresh-cut 'Ágata' potatoes packed under different active modified atmospheres}

\begin{abstract}
The objective of this work was to evaluate chemical and physical characteristics of fresh-cut 'Ágata' potatoes packed under different active modified atmospheres, during refrigerated storage. 'Ágata' potatoes were minimally processed as baby potatoes and packed in nylon multilayer films. The treatments applied were partial vacuum, and atmospheres with $10 \% \mathrm{CO}_{2}, 2 \% \mathrm{O}_{2}, 88 \% \mathrm{~N}_{2}$ and $5 \% \mathrm{CO}_{2}, 5 \% \mathrm{O}_{2}, 90 \% \mathrm{~N}_{2}$. After that, they were stored at $5^{\circ} \mathrm{C}$. Every three days, tubers were evaluated for browning index, polyphenoloxidase and peroxidase activity, firmness, total soluble solids, and titratable acidity. Storage under partial vacuum was the best treatment to control browning and to reduce polyphenoloxidase and peroxidase activities as well as to prevent reduction of total soluble solids, loss of firmness, accumulation of water inside the package and higher titratable acidity. Active modified atmospheres showed faster and sharper browning development, increase of firmness due to tubers dehydration, increase in total soluble solids and lower acidity development comparing with tubers stored under partial vacuum. Storage under partial vacuum showed the best results for maintaining the quality of fresh cut baby potatoes. However, other treatments to maintain firmness freshness, without the development of offflavors and browning, should be evaluated.
\end{abstract}

Index terms: minimal processing, potato, browning, modified atmosphere.

\section{Introdução}

A batata (Solanum tuberosum L.) está entre os dez principais produtos agrícolas brasileiros, e é a hortaliça mais importante para a economia nacional (IBGE, 2002).
Entre as possibilidades de agregação de valor à batata destaca-se o processamento mínimo. Define-se produto minimamente processado como frutas ou hortaliças, ou combinação destas, que tenham sido fisicamente alteradas, mas que permaneçam no estado fresco 
(IFPA,1999). Os estresses mecânicos causados pelo processamento aumentam a taxa de reações bioquímicas responsáveis pelas mudanças na cor, sabor, textura e qualidade nutricional dos produtos minimamente processados (Rocha et al., 2003).

Um dos principais desafios ao processamento mínimo de batatas é a grande susceptibilidade dos tubérculos ao escurecimento, oriundo de reações catalisadas por enzimas, sendo a mais importante a polifenoloxidase (PPO). O escurecimento é iniciado pela oxidação de compostos fenólicos pela PPO. O produto inicial da oxidação é a quinona, que rapidamente se condensa, formando pigmentos escuros insolúveis, denominados melaninas, ou reage não enzimaticamente com outros compostos fenólicos, aminoácidos e proteínas, também formando melanina (Araújo, 2003).

Os fatores mais importantes na evolução da taxa do escurecimento enzimático provocado pela PPO são a concentração de PPO ativa e de compostos fenólicos, o $\mathrm{pH}$, a temperatura e o oxigênio disponível no tecido. A enzima peroxidase (POD) também participa do escurecimento em hortaliças minimamente processadas e está relacionada com processos de cicatrização, como, por exemplo, a lignificação (López-Serrano \& RosBarceló, 1995; Cantos et al., 2002). Sua ação promove a oxidação de compostos fenólicos na presença de peróxido de hidrogênio (Dundford \& Stillman, 1976).

Vários métodos para prevenir o escurecimento enzimático podem ser aplicados em batatas. Todavia, a eficácia dos tratamentos, combinados ou de forma isolada, deve ser verificada. A aplicação de atmosfera modificada ativa ou passiva com baixas concentrações de $\mathrm{O}_{2}$ e altas concentrações de $\mathrm{CO}_{2}$ contribui para o controle do escurecimento e outros processos degradativos do produto, uma vez que reduz a velocidade dos processos aeróbicos e implica baixa disponibilidade de $\mathrm{O}_{2}$ para a atividade da PPO e da POD (Gunes \& Lee, 1997).

A atmosfera modificada passiva é formada a partir da respiração do produto, que consome $\mathrm{O}_{2}$ na embalagem fechada e libera $\mathrm{CO}_{2}$. O próprio polímero da embalagem restringe as trocas gasosas entre os ambientes interior e exterior devido a sua permeabilidade seletiva ao $\mathrm{O}_{2}$ e ao $\mathrm{CO}_{2}$. Após um tempo, o sistema alcança uma atmosfera modificada de equilíbrio com concentrações de $\mathrm{O}_{2}$ menores e de $\mathrm{CO}_{2}$ maiores do que no ar atmosférico.

Já na atmosfera modificada ativa, a mistura gasosa desejada é introduzida na embalagem antes da selagem, acelerando, desta forma, o alcance da atmosfera de equilíbrio no interior da embalagem. A aceleração do equilíbrio atmosférico em embalagens sob vácuo parcial ocorre pelo processo de retirada de ar antes da selagem, diminuindo, o espaço livre (Zagory, 2000).

Níveis reduzidos de $\mathrm{O}_{2}$ reduzem a taxa respiratória de frutas e hortaliças frescas na proporção da concentração de $\mathrm{O}_{2}$, o que se deve, provavelmente, à redução da atividade de oxidases, tais como polifenoloxidases, ácido ascórbico oxidase e ácido glicólico oxidase com baixa afinidade com o $\mathrm{O}_{2}$, em benefício da citocromo oxidase, que tem alta afinidade com o $\mathrm{O}_{2}$ (Kader, 1986).

O objetivo deste trabalho foi avaliar alterações físicas e químicas decorrentes do processamento mínimo de batatas embaladas sob atmosfera modificada ativa durante armazenamento refrigerado do produto.

\section{Material e Métodos}

Batatas da cultivar Ágata, classificação "primeirinha”, foram adquiridas na Ceasa de Brasília e levadas ao Laboratório de Pós-Colheita da Embrapa Hortaliças, onde foram selecionadas, classificadas e lavadas em água potável. Os tubérculos foram descascados por abrasão em máquina processadora (modelo PCED, Siemsem Ltda.) por 180 segundos, em tambor revestido com lixa de 60 mesh, e 36 segundos, no segundo tambor revestido com lixa de 100 mesh. As batatas descascadas foram então enxaguadas em água potável, sanitizadas em água clorada com 150 ppm de cloro ativo por cinco minutos e centrifugadas, por sete minutos, a $800 \mathrm{~g}$. O material foi posteriormente embalado em náilon multicamadas em seladora industrial (Selovac 200B, São Paulo) em porções de 200 g, e armazenado sob refrigeração a $5^{\circ} \mathrm{C}$ por nove dias. Os tratamentos, aplicados no momento da embalagem, foram o vácuo parcial e a aplicação de atmosfera modificada ativa, pela utilização das misturas $10 \% \mathrm{CO}_{2}, 2 \% \mathrm{O}_{2}$ e $88 \% \mathrm{~N}_{2}$ e $5 \% \mathrm{CO}_{2}$, $5 \% \mathrm{O}_{2}$ e $90 \% \mathrm{~N}_{2}$. A cada três dias os tubérculos minimamente processados foram avaliados quanto às seguintes variáveis: índice de escurecimento, atividade enzimática da polifenoloxidase e da peroxidase, firmeza, sólidos solúveis totais e acidez titulável.

O índice de escurecimento (IE) foi determinado por colorimetria $\mathrm{L}^{*} \mathrm{a} \mathrm{b}^{*}$, por meio de leitura no colorímetro Minolta Color Reader CR 10, calculado a partir da fórmula, de acordo com Palou et al. (1999):

$\mathrm{IE}=[100(\mathrm{X}-0,31)] / 0,172 ;$ em que $\mathrm{X}=(\mathrm{a}+1,75 \mathrm{~L}) /$ $(5,645 \mathrm{~L}+\mathrm{a}-3,021 \mathrm{~b})$. 
A atividade das enzimas polifenoloxidase e peroxidase foi determinada segundo o método descrito por Flurkey \& Jen (1978), sendo o extrato lido a $395 \mathrm{~nm}$ para POP e a $470 \mathrm{~nm}$ para POD.

A firmeza foi determinada pelo método da aplanação descrito por Calbo \& Nery (1995).

Os sólidos solúveis totais foram determinados com o auxílio de um refratômetro digital a partir do exsudado das amostras congeladas e descongeladas conforme método da AOAC (1992).

A acidez titulável foi determinada de acordo com método da AOAC (1992), por titulação com $\mathrm{NaOH}$ 0,1N até pH 8,2, com auxílio de um peagâmetro HI8014 (Hanna Instruments).

O experimento foi conduzido em delineamento inteiramente casualizado com 12 tratamentos arranjados em esquema fatorial $3 \times 4$ ( 3 tipos de atmosfera e 4 tempos de amostragem) com três repetições. Os dados foram submetidos à análise de variância e as médias foram comparadas pelo teste de diferença mínima significativa em teste de comparações múltiplas, em que as diferenças entre dois tratamentos maior que a soma de dois desvios-padrões foram consideradas significativas a 5\% de probabilidade (Shamaila et al., 1992).

\section{Resultados e Discussão}

O aumento do índice de escurecimento (IE) foi observado em todos os tratamentos em intensidades diferentes (Figura 1). Embalagens que possuíam inicialmente $5 \% \mathrm{CO}_{2}, 5 \% \mathrm{O}_{2}$ e $90 \% \mathrm{~N}_{2}$ apresentaram maior IE ao lon-

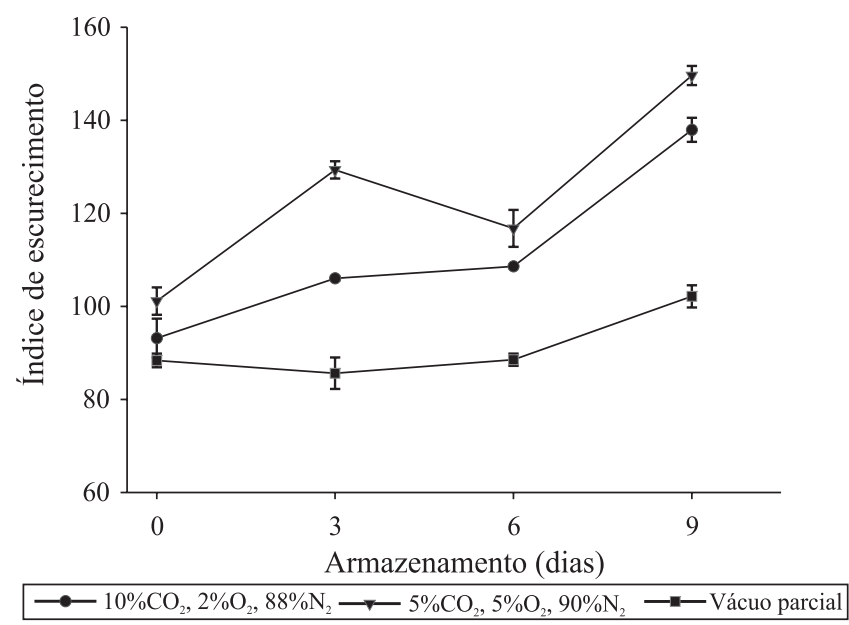

Figura 1. Índice de escurecimento em batatas ‘Ágata’ minimamente processadas, armazenadas sob diferentes atmosferas. Barras verticais representam o desvio-padrão da média. go do armazenamento, seguidas das embalagens com teores iniciais de $10 \% \mathrm{CO}_{2}, 2 \% \mathrm{O}_{2}$ e $88 \% \mathrm{~N}_{2}$ e da embalagem sob vácuo parcial.

O desenvolvimento do escurecimento concorda com observações de Gunes \& Lee (1997). Esses autores demonstraram que uma modificação ativa da atmosfera na embalagem era necessária para estender a vida de prateleira de batatas. Porém a atmosfera modificada por si só não era capaz de evitar o escurecimento. O tratamento por imersão em solução de agentes inibidores do escurecimento seria essencial em batatas minimamente processadas. Os resultados apresentados confirmam esta afirmativa. Entre as atmosferas estudadas, a de $100 \% \mathrm{~N}_{2}$, em sacos de poliolefina multicamada, com alta permeabilidade, foi a mais eficaz. Da mesma forma, Laurila et al. (1998) verificaram que uma embalagem de composto poliamida-polietileno com atmosfera de $20 \% \mathrm{CO}_{2}$ e $80 \% \mathrm{~N}_{2}$ proporcionou a melhor qualidade sensorial para batatas fatiadas tratadas com ácidos cítrico e ascórbico como inibidores de escurecimento, após sete dias de armazenamento, evidenciando a importância da associação entre atmosfera e antioxidantes na manutenção da cor desse produto.

As atividades da PPO e da POD foram superiores em embalagens sem aplicação de vácuo parcial, algumas horas após o processamento e armazenamento em câmara fria (Figura 2). Embalagens sob vácuo parcial apresentaram aumento significativo da atividade enzimática apenas no sexto dia de armazenamento, restabelecendo a atividade inicial, posteriormente, com valores de atividade de POD duas a três vezes menor que os demais tratamentos durante todo o armazenamento.

A eficácia do vácuo em relação ao controle da atividade de enzimas do escurecimento foi também verificada por Rocha et al. (2003), que avaliaram o efeito da embalagem a vácuo na manutenção da qualidade de batatas 'Desirée' minimamente processadas. Esses autores observaram um decréscimo de aproximadamente $50 \%$ na atividade da PPO ao longo dos sete dias de observação e verificaram, adicionalmente, que o vácuo foi eficaz no controle do escurecimento enzimático e de outras variáveis que conferem qualidade ao produto.

Observou-se que o tratamento com maior atividade da polifenoloxidase não apresentou o maior IE durante o armazenamento. O comportamento observado para a atividade da peroxidase nos tratamentos avaliados, por sua vez, sugere maior correlação dessa variável com o escurecimento. 
Cantos et al. (2002) avaliaram o efeito do processamento mínimo sobre a atividade das enzimas polifenoloxidase, peroxidase e fenilalanina amônia-liase e nos compostos fenólicos, em cinco cultivares de batatas. Os autores não encontraram correlação significativa entre o grau ou a taxa de escurecimento e quaisquer das variáveis investigadas. Entretanto, o aumento da atividade da peroxidase, verificada pela síntese de isoperoxidases identificadas por eletroforese, confirmou a indução da atividade desta enzima como fenômeno comum no reino vegetal em resposta a situações de estresse, tais como danos mecânicos. Os autores sugerem que, para melhor compreensão dos fatores limitantes do desenvolvimento do escurecimento em batatas minimamente processadas, estudos sobre estabilidade de membrana, composição lipídica, teor de cálcio, atividade de proteases e práticas agronômicas são necessários. Semelhante ausência de correlação foi encontrada entre grau de escurecimento e atividade enzimática de maçãs durante o armazenamento a $0^{\circ} \mathrm{C}$ (Coseteng \& Lee, 1987).

A firmeza de batatas 'Ágata', minimamente processadas, embaladas em $10 \% \mathrm{CO}_{2}, 2 \% \mathrm{O}_{2}$ e $90 \% \mathrm{~N}_{2}$ e em $5 \% \mathrm{CO}_{2}, 5 \% \mathrm{O}_{2}$ e $88 \% \mathrm{~N}_{2}$, apresentou aumento significativo ao longo do armazenamento, enquanto batatas embaladas sob vácuo parcial não sofreram alterações significativas quanto a essa variável (Figura 3).

Pode-se atribuir o aumento da firmeza em batatas embaladas em $10 \% \mathrm{CO}_{2}, 2 \% \mathrm{O}_{2}$ e $90 \% \mathrm{~N}_{2}$ e em $5 \% \mathrm{CO}_{2}$,
$5 \% \mathrm{O}_{2}$ e $88 \% \mathrm{~N}_{2}$ à perda de água considerável verificada nos tubérculos armazenados sob essas condições, que apresentavam superfície áspera e ressecada. $\mathrm{O}$ aumento na velocidade da perda d’água é o maior problema físico verificado em frutas e hortaliças minimamente processadas. O corte ou descasque expõe os tecidos internos hidratados e aumenta drasticamente a taxa de evaporação de água. A diferença na taxa de perda d'água entre tecidos intactos e danificados varia de cinco a dez vezes em órgãos levemente suberizados, como a cenoura, e até mais de 500 vezes em órgãos intensamente suberizados, como as batatas (Burton, 1982).

O corte e o descasque podem provocar, ainda, a ativação de mecanismos de defesa culminando na deposição de lignina e suberina nas paredes das células danificadas (Dyer et al., 1989; Dixon \& Paiva, 1995), possivelmente seguido da divisão celular sob o tecido suberizado para recomposição da periderme (Burton, 1982). A lignificação após o dano é uma reação enzimática, envolvendo a atividade da fenilalanina amônia-liase em resposta ao estresse (Dixon \& Paiva, 1995). A lignina é um polímero complexo formado a partir de uma mistura de fenilpropanóides simples. Muitos desses compostos são induzidos pelo dano. O ácido clorogênico, os ésteres de alquil ferulato e outros ésteres fenólicos de parede celular podem agir diretamente como componentes de defesa ou podem ser precursores da síntese de lignina, suberina e outras barreiras
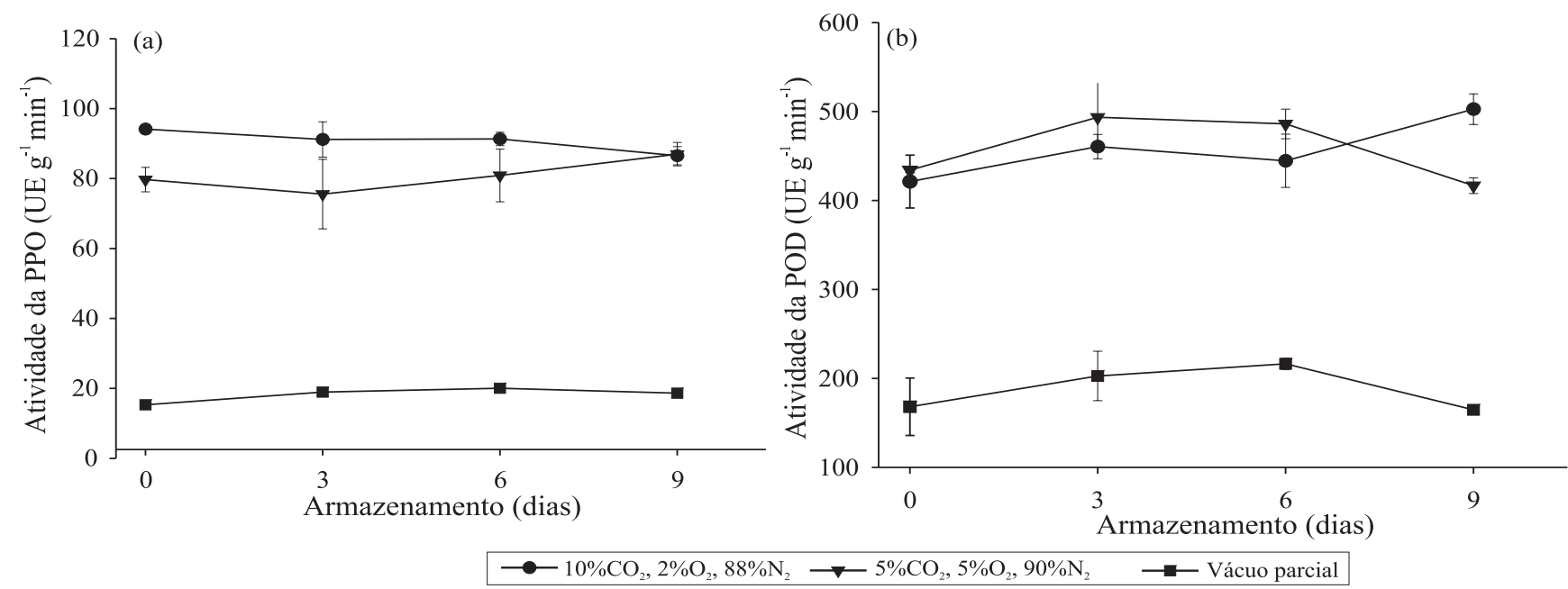

Figura 2. Atividade das enzimas polifenoloxidase (a) e peroxidase (b) em batatas ‘Ágata’ minimamente processadas, armazenadas sob diferentes atmosferas. Barras verticais representam o desvio-padrão da média. 
polifenólicas (Bernards \& Lewis, 1992; Hahlbrock \& Scheel, 1995; Dixon \& Paiva, 1995). A tensão de oxigênio (Wigginton, 1974; Lipton, 1975) e de gás carbônico (Lipton, 1975) pode inibir a lignificação e suberização em batatas danificadas quando os níveis de $\mathrm{O}_{2}$ estão abaixo de $10 \%$ e os de $\mathrm{CO}_{2}$ acima de $5 \%$. Os resultados estão de acordo com estes autores, uma vez que batatas sob atmosfera $10 \% \mathrm{CO}_{2}, 2 \% \mathrm{O}_{2}$ e $99 \% \mathrm{~N}_{2}$ apresentaram menor incremento da firmeza em relação a batatas embaladas a $5 \% \mathrm{CO}_{2}, 5 \% \mathrm{O}_{2}$ e $88 \% \mathrm{~N}_{2}$ (Figura 3). Batatas sob vácuo parcial apresentam menor tensão de oxigênio na embalagem e não apresentaram aumento da firmeza, o que pode confirmar uma relação inversa entre a tensão de $\mathrm{O}_{2}$ e a inibição da síntese de lignina e suberina.

Desta forma, verificou-se que a desidratação e a deposição de lignina e suberina são, provavelmente, os fatores responsáveis pelo aumento na firmeza e outras alterações superficiais observadas em batatas minimamente processadas embaladas na ausência de vácuo. Apesar da manutenção da firmeza a $5^{\circ} \mathrm{C}$, batatas sob vácuo parcial apresentaram superfície enrugada, embalagem encharcada e leve odor desagradável a partir do sexto dia, relacionados a processos fermentativos indesejáveis, o que compromete a aceitação do produto.

Batatas embaladas em atmosferas modificadas ativas de $10 \% \mathrm{CO}_{2}, 2 \% \mathrm{O}_{2}$ e $88 \% \mathrm{~N}_{2}$ e em $5 \% \mathrm{CO}_{2}, 5 \% \mathrm{O}_{2}$

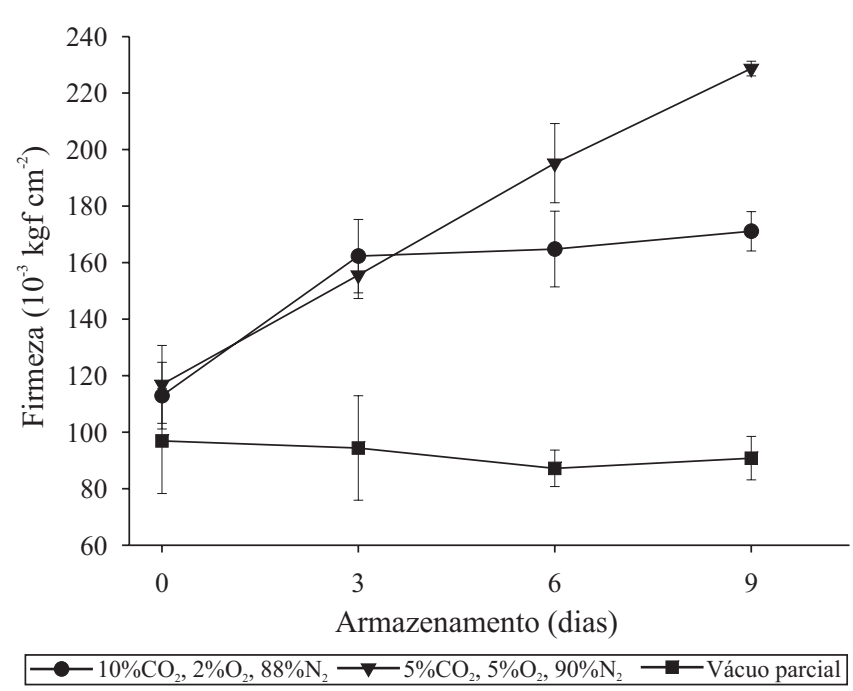

Figura 3. Firmeza em batatas ‘Ágata’ minimamente processadas, armazenadas sob diferentes atmosferas. Barras verticais representam o desvio-padrão da média. e $90 \% \mathrm{~N}_{2}$ apresentam teor de sólidos solúveis totais maior que as batatas sob vácuo parcial (Figura 4). Em todos os tratamentos, foi observada a redução dos sólidos solúveis totais, em concordância com Rocha et al. (2003), que observaram redução do teor de sólidos solúveis totais em batatas 'Desirée' minimamente processadas e embaladas sob vácuo parcial após sete dias de armazenamento a $6^{\circ} \mathrm{C}$.

O comportamento dos teores de sólidos solúveis totais no produto está relacionado aos estresses mecânicos associados ao processamento mínimo, provocando aumento na atividade metabólica dos tubérculos e contribuindo para a degradação de componentes estruturais. Paralelamente, ocorre a conversão do amido em açúcares pelo armazenamento a $5^{\circ} \mathrm{C}$ (Barker, 1968; Isherwood, 1973; Deiting et al., 1998). Posteriormente, o açúcar é consumido nos processos respiratório e fermentativo, com produção de $\mathrm{CO}_{2}$ e água, e ácidos orgânicos, respectivamente. Tais processos contribuem para a redução dos sólidos solúveis totais com o tempo, cujos valores estão associados à diferença entre liberação e degradação de açúcares. Neste contexto, a embalagem sob vácuo parcial parece acarretar menores alterações nesta variável.

Verificou-se não haver diferença significativa na acidez titulável entre os diferentes tratamentos logo após o processamento mínimo, sendo que as batatas minimamente processadas apresentavam acidez em torno de 0,15\% (Figura 5). Os tratamentos com menores con-

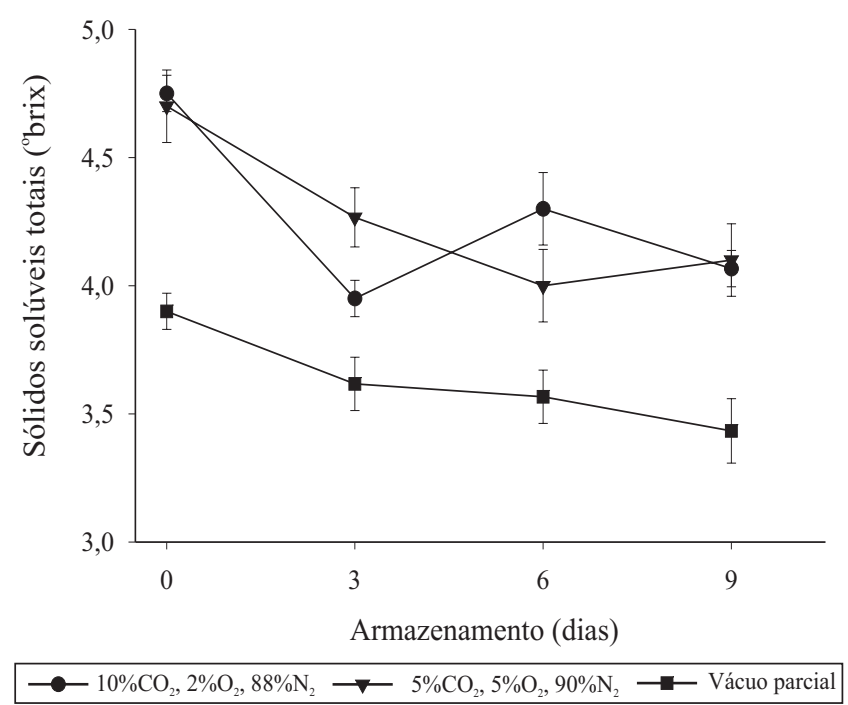

Figura 4. Sólidos solúveis totais ('brix) em batatas 'Ágata' minimamente processadas, armazenadas a $5^{\circ} \mathrm{C}$. Barras verticais representam o desvio-padrão da média. 


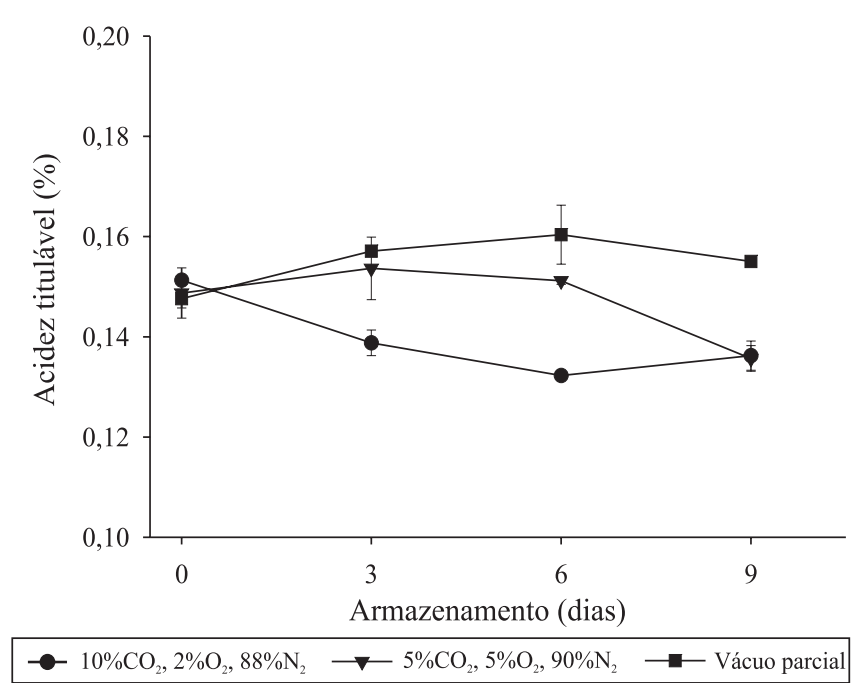

Figura 5. Acidez titulável (\%) em batatas ‘Ágata’ minimamente processadas, armazenadas a $5^{\circ} \mathrm{C}$. Barras verticais representam o desvio-padrão da média.

centrações de oxigênio na embalagem apresentaram maior acidez titulável no nono dia, provavelmente em decorrência de processos anaeróbios. Segundo Smith (1977), a acidez titulável de batatas varia de $0,85 \%$ a $1,15 \%$. O valor determinado para a cultivar Ágata intacta foi de $0,15 \%$, bastante inferior ao relatado pelo autor, porém admissível ao se considerar as diferenças varietais. Rocha et al. (2003) avaliaram o efeito da embalagem a vácuo em batatas 'Desirée' minimamente processadas e observaram um aumento na acidez titulável após sete dias de armazenamento, o que está de acordo com os resultados encontrados para a cultivar Ágata. Comparativamente, Pilon (2003) avaliou a acidez titulável em salada mista (batata e vagem) minimamente processada e verificou, entre os tratamentos avaliados, que o vácuo parcial apresentou a maior acidez ao fim da avaliação.

\section{Conclusões}

1. Batatas embaladas em atmosferas modificadas ativas sem vácuo apresentaram ressecamento superficial, aumento da firmeza, intenso desenvolvimento do escurecimento, aumento nas atividades das enzimas polifenoloxidase e da peroxidase e redução da acidez titulável e dos sólidos solúveis totais após nove dias de armazenamento.

2. O armazenamento sob vácuo parcial foi mais eficaz no controle do escurecimento e das atividades das enzimas polifenoloxidase e peroxidase em batatas
‘Ágata' minimamente processadas, sendo, apesar disso, observado aumento do IE nestas condições; houve redução dos sólidos solúveis totais, aumento da acidez titulável, redução da firmeza e encharcamento da embalagem, conferindo aspecto desagradável às embalagens sob vácuo parcial.

3. A associação de tratamentos antioxidantes com estas atmosferas deve ser avaliada como alternativa para obtenção de um produto mais estável no que diz respeito à firmeza, cor e aspecto de frescor.

\section{Agradecimentos}

Ao Prodetab (acordo BIRD/EMBRAPA, Projeto 019), pelo apoio financeiro; à Agropecuária Distrito Federal (ADF), pelo fornecimento das batatas utilizadas no estudo.

\section{Referências}

ARAÚJO, J.M.A. de. Química de alimentos: teoria e prática. 3.ed. Viçosa: Ed. da UFV, 2003. 475p.

ASSOCIATION OF OFFICIAL ANALYTICAL CHEMISTS AOAC. Official methods of analysis of the Association of Official Analytical Chemistry. 11.ed. Washington, 1992. 1115p.

BARKER, J. Studies in the respiratory and carbohydrate metabolism in plant tissue. XXIV. Influence of a decrease in temperature on the contents of certain phosphate esters in plant tissues. New Phytologist, v.67, p.487-493, 1968.

BERNARDS, M.A.; LEWIS, N.G. Alkyl ferulates in wound healing potato tubers. Phytochemistry, v.31, p.3409-3412, 1992.

BURTON, W.G. Post-harvest physiology of food crops. London: Longman, 1982. 339p.

CALBO, A.G.; NERY, A.A. Medida de firmeza em hortaliças pela técnica de aplanação. Horticultura Brasileira, v.13, p.14-18, 1995.

CANTOS, E.; TUDELA, J.A.; GIL, M.I.; ESPÍN, J.C. Phenolic compounds and related enzymes are not rate-limiting in browning development of fresh-cut potatoes. Journal of Agricultural and Food Chemistry, v.50, p.3015-3023, 2002.

COSETENG, M.Y.; LEE, C.Y. Changes in apple polyphenoloxidase and polyphenol concentrations in relation to degree of browning. Journal of Food Science, v.52, p.985-989, 1987.

DEITING, U.; ZRENNER, R.; STITT, M. Similar temperature requirement for sugar accumulation and for the induction of new forms of sucrose phosphate synthase and amylase in cold-stored potato tubers. Plant Cell and Environment, v.21, p.127-138, 1998.

DIXON, R.A.; PAIVA, N.L. Stress-induced phenylpropanoid metabolism. Plant Cell, v.7, p.1085-1097, 1995.

DUNDFORD, H.B.; STILLMAN, J.S. Function and mechanism of action of peroxidases. Coordination of Chemistry Reviews, v.19, p.187-251, 1976. 
DYER, W.E.; HENSTRAND, J.M.; HANDA, A.K.; HERRMANN, K.M. Wound induces the first enzyme of the shikimate pathway in Solanaceae. Procedures of National Academic Science, v.86, p.7370-7373, 1989.

FLURKEY, W.H.; JEN, J.J. Peroxidase and polyphenoloxidase activities in developing peaches. Journal of Food Science, v.43, p.1826-1828, 1978.

GUNES, G.; LEE, C.Y. Colour of minimally processed potatoes as affected by modified atmosphere packaging and antibrowning agents. Journal of Food Science, v.62, p.572-575, 1997.

HAHLBROCK, K.; SCHEEL, D. Physiology and molecular biology of phenylpropanoid metabolism. Annual Review of Plant Physiology and Plant Molecular Biology, v.40, p.347-369, 1989.

INSTITUTO BRASILEIRO DE GEOGRAFIA E ESTATÍSTICA IBGE. Sistema IBGE de recuperação automática. Produção agrícola municipal 2002. Disponível em: <http://www.sidra.ibge.gov.br/bda/ acervo/acervo2.asp? $\mathrm{e}=\mathrm{v} \& \mathrm{p}=\mathrm{pa} \& \mathrm{z}=\mathrm{t} \& \mathrm{o}=11>$. Acesso em: 16 jun. 2004.

INTERNATIONAL FRESH CUT PRODUCE ASSOCIATION IFPA. Fresh-cut produce handling guidelines. 3.ed. Newark: Produce Marketing, 1999. 39p.

ISHERWOOD, F.A. Starch-sugar interconversion in Solanum tuberosum. Phytochemistry, v.12, p.2579-2591, 1973.

KADER, A.A. Biochemical and physiological basis for effects of controlled and modified atmospheres on fruits and vegetables. Food Technology, v.40, p.99-104, 1986.

LAURILA, E.; KERVINEN, R.; AHVENAINEN, R. The inhibition of enzymatic browning in minimally processed vegetables and fruits. Review article. Post Harvest News and Information, v.9, p.53-66, 1998.

LIPTON, W.J. Controlled atmospheres for fresh vegetables and fruits - why and when. In: HAARD, N.F.; SALUNKHE, D.F. (Ed.).
Postharvest biology and handling of fruits and vegetables. Westport, CT: AVI, 1975. p.130.

LÓPEZ-SERRANO, M.; ROS-BARCELÓ, A. Peroxidase in unripe and processing ripe strawberries. Food Chemistry, v.52, p.157160, 1995.

PALOU, E.; LÓPEZ-MALO, A.; BARBOSA-CÁNOVAS, G.V.; WELTI-CHANES, J.; SWANSON, B.G. Polyphenoloxidase activity and color of blanched and high hydrostatic pressure treated banana puree. Journal of Food Science, v.64, p.42-45, 1999.

PILON, L. Estabelecimento de vida útil de hortaliças minimamente processadas sob atmosfera modificada e refrigeração. 2003. 128p. Dissertação (Mestrado) - Escola Superior de Agricultura Luiz de Queiroz, Piracicaba.

ROCHA, A.M.C.N.; COULON, E.C.; MORAIS, A.M.M.B. Effects of vacuum packaging on the physical quality of minimally processed potatoes. Food Service Technology, v.3, p.81-88, 2003.

SHAMAILA, M.; POWRIE, W.D.; SKURA, B.J. Sensory evaluation of strawberry fruit stored under modified atmosphere packaging (MAP) by quantitative descriptive analysis. Journal of Food Science, v.57, p.1168-1172, 1992.

SMITH, O. Potatoes: production, storing, processing. 2.ed. Westport: AVI, 1977. 642p.

WIGGINTON, M.J. Effects of temperature, oxygen tension and relative humidity on the wound-healing process in the potato tuber. Potato Research, v.17, p.200-214, 1974.

ZAGORY, D. What modified atmosphere packaging can and can't do for you. In: ANNUAL POSTHARVEST CONFERENCE AND TRADE SHOW, 16., 2000, Washington. Selection of articles written by Davis Fresh Technologies consultants and associates. Disponível em: <http://www.davisfreshtech.com>. Acesso em: 17 jun. 2004.

Recebido em 3 de março de 2005 e aprovado em 21 de julho de 2005 